\title{
ANALISIS MAKNA DESAIN FONT JUDUL FILM DALAM POSTER SEBAGAI MEDIA PROMOSI
}

\section{Lutfiyana Indriani Rahma ${ }^{1)}$, Latifah Rizqa Utami ${ }^{2)}$}

Program Studi Desain Komunikasi Visual, Fakultas Bahasa Dan Seni, Universitas Indraprasta PGRI

Jl. Nangka 58 C Tanjung Barat, Jakarta Selatan, 12530, Indonesia

Email:lutfiyair@gmail.com

\begin{abstract}
Abstrak
Suatu judul film merupakan salah satu elemen penting yang terdapat pada poster film yang memberikan gambaran makna film yang menjadikan tipografi sebagai unsur pendukungnya. Gaya atau tipe huruf dalam sebuah kata atau kalimat bukan saja dapat memberikan suatu makna yang mengacu kepada sebuah objek ataupun gagasan, tetapi juga memiliki kemampuan untuk menyuarakan suatu citra ataupun kesan secara visual karena huruf mempunyai nilai fungsional dan nilai estetik. Penulisan ini bertujuan memberikan inspirasi objek penelitian untuk menentukan tipe font yang sesuai dengan makna dari judul sebuah film. Metode penelitian yang digunakan ialah dengan pendekatan kualitatif. Hasil penelitian ini menegaskan bahwa pemilihan tipografi/font yang tepat untuk diaplikasikan pada poster film bertujuan agar audience bisa menafsirkan film yang akan dilihat sekaligus sebagai bahasa verbal yang dibuat menjadi simbol visualnya.
\end{abstract}

Kata Kunci: Font, Judul Film, Poster.

\begin{abstract}
A film title is one of the important elements contained in a film poster that provides an overview of the meaning of a film that uses typography as a supporting element. The style or type of letter in a word or sentence can not only give a meaning that refers to an object or idea, but also has the ability to voice an image or visual impression because letters have functional and aesthetic values. This writing aims to inspire the object of research to determine the type of font that matches the meaning of the title of a film. The research method used is a qualitative approach. The results of this study confirm that the selection of the right typography/font to be applied to film posters aims to make the audience able to interpret the film that will be seen as well as verbal language that is made into its visual symbol.
\end{abstract}

Keywords: Font, The Movie Title, Poster.

Correspondence author: Lutfiyana Indriani Rahma, lutfiyair@gmail.com, Jakarta, and Indonesia

This work is licensed under a $C C-B Y-N C$ 


\section{PENDAHULUAN}

Judul film sangatlah penting tentunya dalam setiap cerita yang difilmkan. Suatu judul harus dapat memberikan gambaran makna film agar dapat menarik perhatian calon audiens untuk mencari tahu isi ceritanya yang ada dalam film tersebut. Judul menjadi poin utama dalam suatu film yang diletakkan dalam poster film yang akan menjadi media promosi film tersebut. Sebab itu judul pada film juga berhubungan dengan tipe font yang sesuai dengan makna pada judul, sehingga dapat menggambarkan dengan jelas dan menjadi ciri khas dari poster filmnya. Desain dan makna dalam font yang digunakan juga menjadi penting dalam membuat konsep pada desain poster film agar sesuai dengan konsep cerita dalam film dan dapat menyampaikan pesan dengan baik dan jelas kepada audiens.

Judul film merupakan bagian dari rancangan grafis yang diciptakan oleh desainer grafis dengan harapan mewakili konsep, karakteristik serta kekuatan kata-kata guna mengekspresikan cerita filmnya. Salah satu cara yang dapat mendongkrak jumlah audience untuk menonton film yaitu dengan mempromosikan film-film tersebut melalui media poster. Dengan desain poster film yang menarik serta dapat menggambarkan inti dari cerita film itu sendiri dinilai dapat menarik banyak audiens untuk menonton. Poster film merupakan poster yang bertujuan untuk mempromosikan film tersebut. Poster film harus bisa 'bercerita'. Semua elemennya harus bisa saling mendukung satu sama lain untuk menggambarkan pesan filmnya dan membuat target audiens tertarik untuk menonton (Rustan, 2010).

Font pada judul film merupakan salah satu elemen penting yang terdapat pada poster film. Tipe font yang digunakan harus bisa mewakili konsep dan karakteristik dari cerita film itu sendiri. Pemilihan font yang tepat pada judul film tidak hanya dapat memberikan gambaran pada target audiens mengenai isi cerita film tersebut tetapi juga dapat menarik dan memancing rasa ingin tahu mereka untuk menonton. Font tidak dilepaskan dari perjalanan hidup manusia. Tipografi adalah elemen grafis yang paling mudah dibaca. Namun, melalui kata-kata yang terdiri dari huruf dan oleh huruflah yang memandu pemahaman pembaca pesan atau ide (Sudiana, 2001:1).

Menurut Soewardikoen (dalam Rahman dkk., 2018) dalam periklanan kata dan gambar saling mempengaruhi sehingga membentuk impresi. Font, huruf, atau tipografi dalam sebuah iklan dapat memengaruhi konsumen untuk mengambil keputusan sehingga penting untuk diperhatikan. Penelitian lain seperti yang dilakukan oleh Suprapto (2020) menyimpulkan bahwa huruf merupakan pendukung aktivitas branding, huruf juga bisa memberikan kesan pada nilai identitas (identity) dan citra (image). Menurut Rustan (dalam Januariyansah, 2018), pemilihan huruf tidak hanya berdasarkan pada selera saja, tetapi setiap huruf membawa sifat kepribadian sendiri-sendiri sehingga huruf dipilih erat kaitannya dengan citraan yang akan dibentuk. Menurut Hanik dkk. (2011) ukuran huruf yang berbeda-beda bertujuan untuk memudahkan dalam mengidentifikasi serta membaca setiap item data pada suatu formulir. Dari beberapa penelitian di atas dapat disimpulkan bahwa huruf dipilih penuh dengan alasan, bukan tanpa alasan. Bayak alasan yang mendasari pemilihan huruf, di antaranya untuk membentuk impresi, sebagai pendukung branding, mencerminkan kepribadian atau jati diri.

Tujuan dari penelitian ini dalam pemilihan jenis huruf pada judul film dihadapkan dengan karakter yang ingin diungkapkan. Rangkaian huruf dalam sebuah kata atau kalimat bukan saja dapat memberikan suatu makna yang mengacu kepada sebuah objek ataupun gagasan, tetapi juga memiliki kemampuan untuk menyuarakan suatu citra ataupun kesan secara visual, karena huruf mempunyai nilai fungsional dan nilai estetik. Seperti yang ditulis (Sihombing, 2001) font atau tipografi merupakan konsep yang abstrak, seperti halnya musik. Dengan mendengarkan sebuah lagu kita dapat merangkum karakteristik, kesan, dan suasana hati, seperti perasaan gembira, sedih, optimisme, tenteram ataupun romantis.

\section{METODE PENELITIAN}

Pendekatan metode penelitian yang digunakan dalam penelitian ini merupakan pendekatan kualitatif. Pendekatan kualitatif didefinisikan "Metode penelitian kualitatif adalah proses menjaring informasi dan kondisi yang sebenarnya dalam kehidupan suatu objek yang dihubungkan dengan pemecahan suatu masalah baik dari sudut pandang teoretis maupun praktis" (Nawawi dan Hadari, 1995). Metode kualitatif yang digunakan penulis dalam proses pengumpulan data adalah observasi. Melalui observasi dapat menjelaskan tentang menentukan 
gaya font yang tepat sesuai makna pada penulisan judul film dalam poster sebagai media promosi, untuk dapat membantu dalam pembuatan penulisan ini.

Penelitian ini merupakan studi kasus dengan analisis kualitatif berdasarkan pada data primer dan sekunder yang diperoleh langsung melalui observasi lapangan langsung kepada objek penelitian dan nara sumber. Data primer tersebut meliputi mencari tahu tentang, pemilihan jenis huruf pada judul film dihadapkan dengan karakter yang ingin diungkapkan. Hal tersebut relevan dengan teori dari Danton Sihombing bahwa "tipografi/font merupakan representasi visual dari sebuah bentuk komunikasi adalah sifat verbal dan properti visual dan efektif", yang digunakan untuk mengurai rumusan masalah (Sihombing, Anggota DGI. 2001:58). Sumber data yang penulis gunakan terdiri dari data primer dan data sekunder. Data primer diperoleh dari pendapat beberapa orang mahasiswa dan masyarakat umum yang suka menonton film. Data sekunder diperoleh dari sumber literasi desk studi, infomasi tentang penggunaan font atau gaya tipografi dan desain poster film dari internet dan media promosi lainnya seperti majalah, dan televisi.

\section{HASIL DAN PEMBAHASAN}

Judul Film adalah nama yang digunakan dalam film yang dapat menyiratkan secara singkat isi atau maksud dalam film tersebut. Judul adalah hal pertama yang dilihat pada sebuah film yang akan ditayangkan. Hal pertama yang dilihat dalam sebuah film adalah judul nya. Judul film yang ditulis dengan tepat merupakan daya tarik tersendiri yang mendorong seseorang untuk menonton film tersebut. Judul nya menarik maka akan mendatangkan banyak audiens yang ingin tahu pada film tersebut. Hal lain yang membuat sebuah judul film menjadi menarik adalah penggunaan tipografi pada judul film tersebut. Pemilihan tipografi pada film pada suatu negara juga berbeda -beda. Misalnya, Ciri khas film India, misalnya, yang terkenal dengan tarian perut, percintaan, dan konflik keluarga seringkali penampilan tipografinya hampir sama, baik dari stroke, warna, outline bentuk huruf serta komposisinya.

Film "superhero" seperti Batman, Superman, Spiderman yang pemilihan jenis hurufnya tidak jauh berbeda dengan karakter filmnya, perubahannya disesuaikan dengan trend karakter tipografi pada zaman dibuatnya film tersebut. Perubahan tersebut merupakan terobosan dalam dunia tipografi, khususnya dengan perubahan yang revolusioner dari perangkat desktop publishing. Pengaruh teknologi digital pada intinya tidak mengubah fungsi huruf sebagai perangkat komunikasi visual, namun teknologi komputer menyajikan spektrum dalam menyampaikan pesan lewat huruf, mencitrakan sebuah gaya yang memiliki korelasi dengan khalayak tertentu, di mana desainer grafis memiliki kebebasan menciptakan visualisasi pesan dengan huruf, tidak untuk dibaca, tetapi juga mengekspresikan suasana atau rasa.

\section{Tipografi Film}

Film merupakan media komunikasi dari berbagai teknologi dan unsur-unsur kesenian. Film mewakili realitas dalam bentuk imaji maupun realita. Film menunjukkan yang ditinggalkan pada masa lampau, cara menghadapi masa kini, dan dalam perkembangannya film bukan lagi sebagai usaha menampilkan "citra bergerak" (moving images), namun juga telah diikuti oleh muatan kepentingan tertentu misalnya politik, kapitalisme, hak asasi manusia atau lifestyle seseorang. Perkembangan film begitu pesat, bukan saja dari negara-negara yang sudah maju per-filmnya tetapi juga sampai negara yang memulai menata industri filmnya. Hollywood (USA), Bollywood (India) dan Hongkong merupakan perusahaan yang sudah mengglobalkan film-filmnya. Pesatnya perkembangan film ini juga tampak dari penampilan judul film itu sendiri. Judul film yang ditulis dengan tepat, merupakan daya tarik tersendiri yang mendorong seseorang untuk menonton film tersebut (Kusuma, 2010). bersangkutan:

Berikut ini akan diuraikan beberapa contoh tipografi film menurut karakter cerita film yang

\section{Film Roman Klasik}

Dari dua film yang berbeda angka tahun pembuatannya film Titanic versi lama menggunakan tipografi yang berkesan kokoh, kuat, shadow di belakang huruf tersebut memberikan kesan dimensional. Bentuk tipografi utamanya huruf "A", derajat kemiringan tidak sama dengan huruf-huruf lainnya, posisi tipografi tersebut benar-benar "eye catching". Sementara itu, Titanic versi baru memiliki style lebih modern dengan komposisi simetris pewarnaan lebih elegan dan harmonis (Hartanto, 2003). 

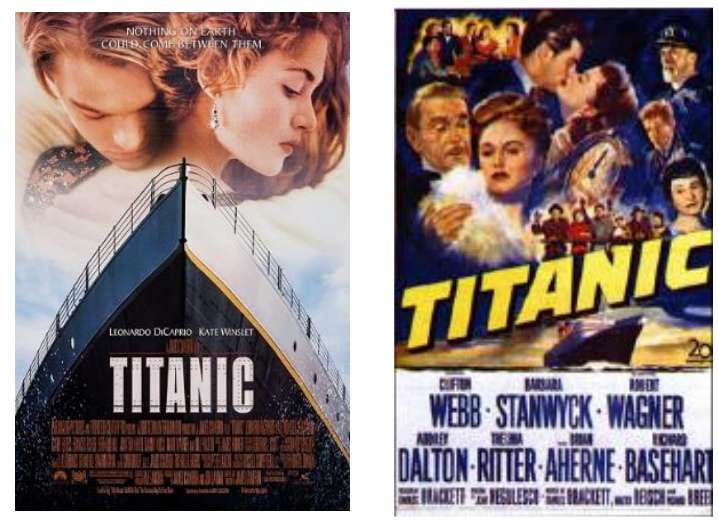

Gambar 1 Poster Film Titanic baru (kiri) Poster Film Titanic lama (kanan)

Layout dari tipografinya dengan menggunakan bentuk huruf Roman Kapital Klasik berserif sangat sesuai dengan karakter kapal Titanic itu yang berkesan mewah, eksklusif, dan klasik. Dari dua film tersebut jelas pemilihan tipografi dan ilustrasi film berpengaruh pada latar belakang waktu pembuatan film tersebut dibuat.

\section{Film Epos Klasik}

Ketiga film dengan setting klasik memiliki karakter yang sama mulai dari model baju tokoh, cerita, suasana, alat perang dan tipografinya. Film Braveheart menggunakan tipografi Roman Kapital Klasik yang hampir sama dengan tipografi film Titanic versi baru tetapi pada huruf "A" lebih memberikan aksen dengan lingkaran kecil atau titik, tidak menggunakan garis.
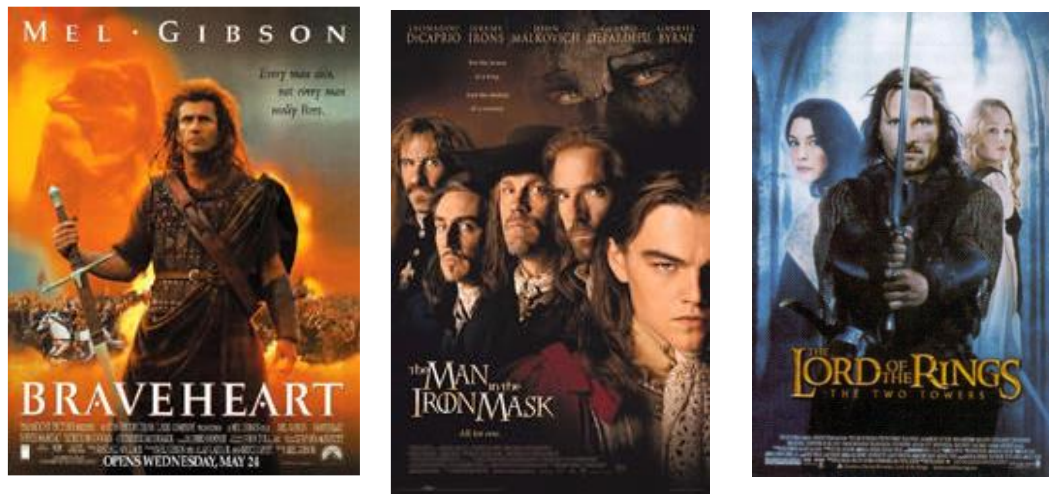

Gambar 2 Poster film Braveheart, The Man In The Iron Mask, The Lord Of The Rings

Karakter huruf roman, yang banyak dipengaruhi budaya kerajaan Romawi, garis tebal tipis pada stroke-nya dengan sudut lengkung menjadi khas pada film bertema setting klasik. Film The Man in The Iron Mask dengan tipografi yang karakter stroke-nya sama dengan Braveheart memodifikasi tipografi dengan kesan "monumental", hal ini bisa dilihat dari komposisi letak judul film tersebut. Huruf M pada kata Man huruf I pada kata Iron dan huruf M pada kata Mask dibuat lebih besar dan panjang ke bawah, mirip dengan bentuk-bentuk bangunan arsitektural monumen. Aksen huruf $\mathrm{O}$ pada kata Iron dibubuhi suatu tanda ikonografi yang menguatkan kesan klasik. Kalau diamati bentuk huruf $\mathrm{O}$ pada kata Iron dilihat dari stroke-nya merupakan prototype struktur dasar bangunan-bangunan arsitektural Romawi seperti bentuk lengkung pada bangunan kubah. Film The Lord of The Ring (The Two Towers), kesan dimensional tampak sekali dari bentuk tipografi judul filmnya. Dengan menggunakan jenis huruf "Old Style" yang mempunyai ciri khas bertemunya stem dan serif membuat sudut lengkung, kemudian stroke huruf yang tebal-tipisnya 
sangat kontras, kesan monumental lebih jelas dibanding judul film The Man in The Iron Mask karena judul film The Lord Of The Ring menggunakan tekstur dalam stroke tipografinya. Tekstur yang dibuat dengan menggunakan efek pada komputer grafis ini lebih berkesan seperti pagar rumah kuno yang berkarat. Penggunaan tekstur lebih memperkuat karakter tipografi yang semakin kokoh, klasik, kuat, seperti karakter pada cerita filmnya.

\section{Film Superhero}
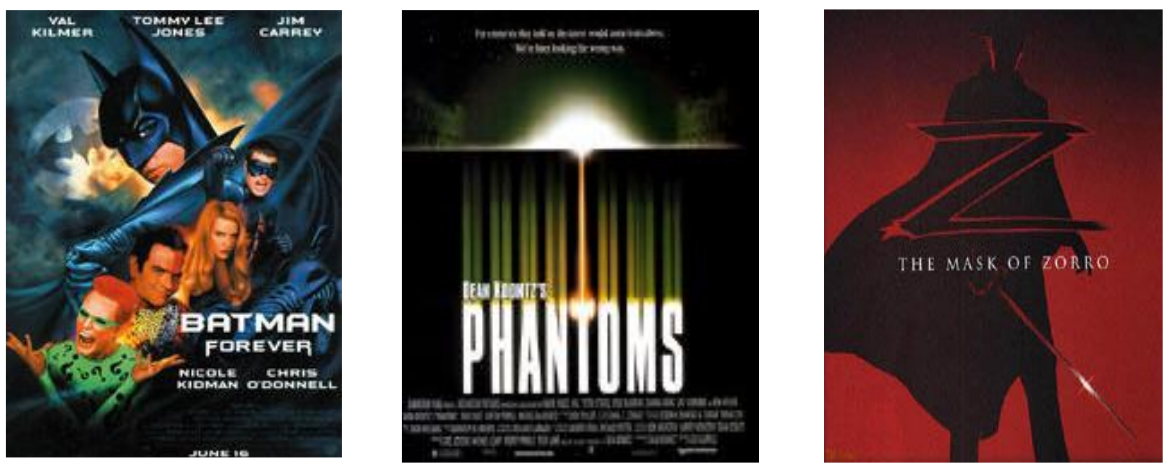

Gambar 3 Poster Film Batman Forever, Phantoms, The Mask of Zorro

Film Batman Forever menggunakan custom typeface jenis Batman Forever Roman, sebuah jenis font yang dibuat khusus oleh Maseeh Ravani dan Mark Van Bronkhorst untuk merefleksikan karakteristik film tersebut dengan memberikan action kuat, serta memiliki paduan nuansa modern dan elegan (Sihombing, 2001). Stroke pada tipografi Batman Forever ini kalau diamati mengambil idea dari bentuk-bentuk runcing, sebagai karakter khas kontur dari tokoh Batman. Tampilan poster film Phantoms sama sekali tidak memperlihatkan wajah Phantoms. Kekuatan poster film ini terletak pada ilustrasi dan judul filmnya. Tipografi yang menggunakan font jenis Haettenschweiler mengungkapkan kesan misterius dengan efek hurufnya yang dibuat motion blur ke bawah, aksentuasi judul film terletak pada $\mathrm{T}$ pada judul filmnya. Bagi seseorang yang belum pernah sama sekali mengetahui tokoh superhero Phantoms mungkin akan menebak dan dibuat penasaran melihat tipografi judul film tersebut. Komposisi tipografi judul film The Mask of Zorro tenggelam lebih terlihat inisial Z sebagai inisial dari Zorro si superhero. Pemilihan tipografi transitional yang di-ekspand, dengan ciri khas pertemuan stem dan serif lengkung ini dibuat seperti pada bentuk tipografi Batman Forever yang mengambil bentuk runcing. Bentuk runcing pada film The Mask of Zorro terletak pada serifnya, dipilih serif karena mengambil ide runcing goresan pedang sebagai senjata andalan Zorro.

\section{SIMPULAN}

Tipografi merupakan salah satu elemen yang bisa mempengaruhi dan dipengaruhi oleh elemen desain yang lain, tidak bisa berdiri sendiri. Hal ini tampak sebagaimana dalam contoh penggunaan tipografi dalam judul desain poster film. Tipografi jenis Old Style lebih banyak digunakan untuk tipografi judul film tema klasik. Stroke tipografinya lebih mendekatkan pada karakter jenis font roman yang dalam sejarahnya merupakan capitalis quadrata (Danton, 2001) yang banyak digunakan pada abad ke-2 hingga abad ke-5. Film Braveheart, The Man in The Iron Mask, The Lord of The Rings (The Two Towers) menggunakan huruf serif sebagai salah satu ciri khas huruf roman, perbedaannya pada modifikasi dan penggunaan tekstur pada judul film. Tipografi yang memiliki perlakuan spesial efek khusus biasanya lebih memberikan kesan dramatik dari tipografi tersebut seperti pada film "superhero", misalnya film Phantoms yang ditambah spesial efek motion blur yang memberi kesan bayangan lari. Penggunaan huruf dengan efek khusus yang dibantu sarana komputer grafis yang canggih akan memudahkan menciptakan tipografi digital. 
Pada film Titanic rancangan tipografinya memiliki korelasi dengan periode tertentu dan tipografi yang mewakili karakteristik pada masa itu. Perancangan tipografi pada judul film tidak bisa dianggap sepele, karena harus memenuhi beberapa persyaratan antara lain readability (mudah dibaca), gaya, dan keserasian. Misalnya, tentang advanced teknologi maka huruf atau style yang digunakan harus cocok dengan teknologi tersebut. Tipografi judul film adalah salah satu bagian dari elemen poster film di samping ilustrasi atau gambar, kedua unsur ini tidak bisa berdiri sendiri dan harus merupakan satu kesatuan yang efektif. Tipografi yang sudah dirancang harus menjamin agar audience bisa menginterpretasikan judul film tersebut. Tipografi pada judul film merupakan sebuah visualisasi rancang grafis yang dibuat sedemikian rupa supaya audience bisa menafsirkan film yang akan dilihat sekaligus sebagai bahasa verbal yang dibuat menjadi simbol visual melalui tatanan atau komposisi rancang huruf yang dipilih tidak asal-asalan tetapi melalui sebuah proses identifikasi bisa dari karakter peran tokoh, cerita, setting, bahkan trend yang sedang berlaku saat itu.

\section{DAFTAR PUSTAKA}

Hanik, S. K., Sudra, R. I., \& Rohmadi, R. M. D. (2011). Analisis desain formulir laporan operasi (Rm 16) di Rumah Sakit Umum Daerah Kabupaten Karanganyar. Rekam Medis, 5(2).

Hartanto, D. D. (2003). Pemilihan tipografi pada judul film. Nirmana, 5(2).

Januariyansah, S. (2018). Analisis desain logo berdasarkan teori: Efektif dan efisien. Yogyakarta: Universitas Negeri Yogyakarta.

Kusuma, A. (2010). Perempuan dan budaya patriarkhi dalam film "Berbagi Suami" Karya Sutradara Nia Dinata. Jurnal Ilmu Komunikasi.

Nawawi, H., \& Hadari, M. (1995). Instrumen penelitian bidang sosial. Yogyakarta: Gajah Mada University Press.

Rahman, N. N., Utami, R. S., \& Raden, A. Z. M. (2018). Analisis tipografi pada spanduk pemasaran perumahan. Jurnal Desain, 5(03), 250-257.

Rustan, S. (2009). Mendesain logo. Jakarta: PT Gramedia Pustaka Utama.

Sihombing, D. (2001). Tipografi dalam desain grafis. Jakarta: PT Gramedia

Sudiana, D. (2001). Tipografi: Sebuah Pengantar. Mediator: Jurnal Komunikasi, 2(2), 325-335.

Suprapto, R. (2020). Analisis visual perancangan huruf berlatar ornamen. JURNAL ADAT-Jurnal Seni, Desain \& Budaya Dewan Kesenian Tangerang Selatan, 2(3), 6-16. 